\title{
BIBLIOGRAFIA
}

\section{Bibliografía cronológica de la obra de Julián del Casal}

Una de las mayores dificultades de la crítica modernista, y la que más polémicas ha ocasionado, se encuentra en el movedizo terreno de las prelaciones. Se pueden indicar tendencias, preferencias, atisbos; pero en muy pocos casos se puede establecer cronológicamente el hallazgo de una frase o la fecha de un pronunciamiento profético. Además, la obra modernista nace en publicaciones periódicas de vida efímera que en algunos casos han desaparecido por completo.

La presente bibliografía sirve para clarificar algunas de las teorias sobre los orígenes del modernismo. Demuestra que Casal en 1885 estaba interesado en Manuel Reina, pero que en 1886 escribía sobre el rey de los cisnes, Luis de Baviera. A principios de 1887 estaba traduciendo a Baudelaire, a quien imitó en muchos poemitas en prosa, y a fines del mismo año leía a León Tolstoi. Catulle Mendès no aparece hasta marzo de 1888, el año del primer $A z u l$. El lento paso del postomanticismo al modernismo se puede evaluar con absoluta precisión si se leen las poesías de Julián del Casal en su estricto orden cronológico, tal como aparecieron día a día, no de libro en libro, donde las mezcló caprichosamente. Hay que notar, también, que salvo en el extraordinatio caso del soneto "Mis amores", Casal muy pocas veces alteró sus poesías.

\section{ABREVIATURAS:}

HE La Habana Elegante, revista cubana de la cual no hay una edición completa. Se consultó, una parte, en la Biblioteca de la Sociedad Económica de Amigos del País de La Habana, otra en la Biblioteca del Centro 
Gallego de La Habana, y los primeros números en la colección particular de los descendientes de su director, Enrique Hernández Miyares.

F El Figaro, revista cubana que se encuentra completa en la Biblioteca Nacional de La Habana.

Otras publicaciones aparecen con nombre completo. El Pais era un periódico de buena circulación; en cambio El Ensayo era apenas una hoja amarillenta que apareció durante poco tiempo. Estas publicaciones están también en la Sociedad Económica.

\section{1}

PoEsías

"Una lágrima", El Ensayo (febrero-13).

"El poeta y la sirena", a mi buen amigo Carlos Noreña, El Ensayo (marzo, 5).

"Huérfano" (A la señora doña Clara Krick, a la buena amiga de mi des. graciada madre) El Ensayo (marzo, 27).

1885

\section{POESÍAS}

"Nocturno", $H E$ (abril 19). Hay que distinguir como el Nocturno I, que comienza: "En la noche azulada y silenciosa...".

"Desde lejos" HE (diciembre, 6). (Aparece en Hojas al viento, p. 32, con el título "Ausencia").

\section{PROSA}

"Manuel Reina" $H E$ (diciembre, 20).

1886

PoEsías

"Acuarela", $H E$ (enero, 3).

"Luz y sombra", HE (enero, 17). En Hojas al viento, p. 19, con el título "Tras la ventana".

"Lazos de amor, a un amigo", $F$ (enero, 28). 
"Las Palomas", de Teófilo Gautier, $F$ (abril, 8).

"El deseo de una rosa". A Manuel de la Cruz, HE (junio, 13). En Hojas al viento, p. 50, con el título "El anhelo de una rosa".

"Del libro negro", $H E$ (junio, 27).

"El adiós del polaco", $F$ (julio, 15).

"Mis amores, $H E$ (julio, 18). (Con notables variantes en Hojas al viento).

"El Puente", imitación de Víctor Hugo, HE (julio, 25).

"Amor en el claustro". (Dedicada a J. M. de Céspedes) HE (agosto 1).

"Intima". (Imitación F. Coppee) $F$ (agosto, 12).

"A una mexicana", HE (agosto, 29). En Hojas al viento como "A Olimpia", de Hugo.

"El anhelo del monarca", $H E$ (septiembre, 26).

"El sueño en el desierto", $H E$ (octubre, 17).

PROSA

"Historia de unos versos", $H E$ (mayo, 2). (Sobre Nieves Xenes).

"Solos. Cap. X: El Viaje a Venecia", $F$ (septiembre, 2).

"Círculo habanero. Impresiones de la última velada", $H E$ (octubre, 3).

"Los siete castillos del rey de Baviera. El Castillo de Chienssee" (Albert Bataille). HE (octubre, 17).

"La felicidad y el arte". (Fantasía) HE (noviembre, 14).

"Benjamín de Céspedes", $F$ (diciembre, 28).

\section{7}

POE:ÍAS

"Desolación", He (octubre, 3).

"Las mujeres", $F$ (octubre, 27).

"Al llegar la noche", $H E$ (noviembre, 6). En Hojas al viento como "Vespertino", p. 69.

"En el álbum de la Srta. María Suárez y Pérez", HE (noviembre, 13).

"La pena. Paráfrasis de Heine", $F$ (diciembre, 19).

"Ofrenda a Mariano Ramiro", F (diciembre, 8). En Hojas al viento, p. 56, como "Ofrenda".

"Estatua de carne", $H E$ (diciembre, 18).

"La urna", $H E$ (diciembre, 25). 


\section{Traducciones}

Pequeños poemas en prosa, de Charles Baudelaire: "El extranjero",

"Los beneficios de la luna", "El Puerto", HE (marzo, 27).

Pequeños poemas en prosa, de Charles Baudelaire: "A una hora de la madrugada", $H E$ (abril, 3).

Pequeños poemas en prosa, de Charles Baudelaire: "La torta", He (abril, 24).

"La moral del juguete", de Carlos Baudelaire, HE (octubre, 16).

"El pecador arrepentido", del Conde León Tolstoi, "El Libcral" (diciembre, 8).

PoEmas EN PROSA

"Los funerales de una cortesana", $H E$ (noviembre, 20).

"El velo", HE (noviembre, 30).

"Sueño", F (diciembre, 28).

1888

Poesías

"Ensueño, en el álbum de una dama", $H E$ (enero, 10). En Hojas al viento, p. 44, como "Quimeras" con notables variantes.

"Vanidad póstuma", a mis amigos, HE (enero, 22).

"Engañada", paráfrasis de L. Stechette, $H E$ (marzo, 3).

"La mayor tristeza", HE (mayo, 13).

"El arte", HE (mayo, 7).

"Manólogo de una rosa marchita". En el álbum de la señorita Cristiana Granados, $F$ (junio, 30). En Hojas al viento, p. 50, dedicado a Ma. nuel de la Cruz con el título "El anhelo de una rosa" y notables variantes.

"A Coralia", $F$ (octubre, 28). En Hojas al viento como "A Berta".

"El sueño en el desierto". (Fascímil) (noviembre, 4). (Reproducción de $H E$, octubre, 1886.)

"La última noche", de L. Bouilhet, HE (noviembre, 11).

\section{Traducciones}

"Viejos labios y joven beso", de Catulle Mendés HE (marzo,25). 


\section{CrónICAS}

"A Enrique en el año nuevo", $H E$ (enero, 8).

"Dos fiestas en una", HE (junio, 17).

\section{CRÍTICA}

"La joven Cuba. Galería Mignón. Ezequiel García", HE (febrero, 12). "La joven Cuba, Galería Mignón. Manuel Serafín Pichardo", HE (mayo, 6).

\section{CoLECCIÓN DE LA Sociedad}

\section{de La Habana}

La Sociedad de La Habana. Ecos mundanos recogidos y publicados por el Conde de Camors. Dedicatoria a Madame Julieta Lambert: Cap. I. "El General Sabás Marín y su familia", $H E$ (marzo, 25).

Cap. III. "La antigua nobleza", $H E$ (abril, 15).

Cap. XI. "La Prensa, fragmentos", $H E$ (mayo, 13).

Cap. IV. "Los antiguos nobles en el extranjero", $H E$ (mayo, 20).

Cap. XIII. "Los pintores", fragmentos, HE (junio, 24).

\section{9}

\section{Ponsías}

"Nocturno", HE (febrero, 17).

"Confidencia", F (marzo, 17).

"Abismo", $H E$ (mayo, 12). Algunas de sus estrofas habían aparecido en $F$ (octubre, 28, 1888), como "A Coralia". Véase en Hojas al Viento, p. 67. como "A Berta".

"Croquis perdido", $H E$ (junio, 23).

"El viajero", F (octubre, 6). En Hojas al viento con el título "En el mar", p. 61. (Compuesta durante el viaje a España).

"Idilio realista. A Raúl Cay", $H E$ (noviembre, 24).

"In memoriam. A Miguel Figueroa, en la muerte de su esposa", F (diciembre, 1).

"Adiós al Brasil del emperador D. Pedro II", $F$ y $H E$ (diciembre, 8), 
Ponmas EN Prosa

"El mejor remedio", HE (marzo, 31).

\section{Cuentos}

"Cuentos inverosímiles. Los dos encuentros", $F$ (febrero, 1).

"Cuentos amigo. La Viudez eterna. A M. Romeu", F (abril, 12).

\section{Crítica LITERARIA}

"El baseball en Cuba. Sobre un libro de Benjamín de Céspedes", La Discusión (noviembre, 28).

"Recuerdos de Madrid. Un poeta mexicano. Francisco de Icaza", $H E$ (febrero, 3).

\section{Crónicas}

"La Nochebuena", Discusión (diciembre, 24).

"Noche y mañana", Discusión (diciembre, 26).

"A través de la ciudad. El centro de Dependientes", Discusión (diciem. bre, 28).

\section{CRÍtica de ARTE}

"Dos retratos de Menocal", Discusión (dicicmbre, 27).

\section{Traducciones}

"La domadora, de Cátulo Mendés", F (octubre, 20).

"Los amores de sesenta años, de Luis Ulbach", HE (septiembre, 15).

\section{Crónicas de Teatro}

"Un estreno y una fiesta", Discusión (diciembre, 30 ).

"Veladas teatrales: Lucas Gómez", Discusión (diciembre, 31).

\section{Colección de LA Sociedad}

\section{de La Habana}

La Sociedad de La Habana. "I El General Salamanca", HE (mayo, 5).

"Bustos femeninos". (Del capítulo "El gran mundo"), HE (mayo, 26). 
1890

\section{PoEsías}

"Mensaje. En el álbum de la Stta. Emestina Oliva", HE (febrero, 9).

En Hojas al viento con el título "En un álbum".

"Versos azules. En el álbum de Miss Ina Lasson", HE (marzo, 16).

"Autobiografía", $H E$ (marzo, 30).

"La canción de la morfina", $H E$ (abr., 20).

"La perla, balada", $H E$ (abr., 27).

"Mis amores", $F$ (mayo, 11).

"Tristissima nox", HE (sept., 14).

"Salomé. A Enrique Fontanills", HE (sept., 21 ).

"Las Oceánidas. A Enrique J. Farona", $H E$ (oct., 5).

"Ante el retrato de Juana Samary", Pdis (oct., 18).

"Vespertino. A Raúl Cay", País (oct., 24).

"Marfiles viejos. Pax Animae", $H E$ (oct., 26): "Blanco y negro", País (nov., 1).

"Mi ensueño", Pais (nov., 15).

"Flores", País (nov., 15).

"Marfiles viejos. A un amigo, enviándole los versos de Leopardi", País (nov, ,22).

"Marfiles viejos. A un amigo, enviándole mi retrato", $H E$ (nov., 30).

"Poesías diversas", $H E$ (dic., 7).

\section{Traducciones}

"Poemitas italianos de la Condesa Lara". A las desconocidas que me los piden. "Yo te amo, Canto nuevo", Discusión (abr., 10).

"La venus de Siracusa, de La vida errante de Maupassant", Discusión, (abr., 19).

"Poemitas en prosa" de Cátulo Mendés. "La estrella, La limosna soñada, El ensueño amargo", Discusión (abr., 25).

"Poemas en prosa" de Carlos Baudelaire. "La desesperación de la vieja, El confiteor del artista, El perro y el frasco"., Discusión (abr., 28).

"Poemas en prosa", de Carlos Baudelaire. "Un hemisferio en una cabellera", Discusión (abr., 29).

"Poemas en prosa", de Carlos Baudelaire. "El loco y la venus", Discusión (mayo, 8). Nota: Conjuntamente con estas nuevas traducciones reproduce otras publicadas anteriormente. 


\section{CríticA LITERARIA}

"Un almanaque", Discusión (ene., 17). (Sobre "La ilustración nacional").

"Cuba por fuera", Discusión (feb., 7). (Sobre T. G. Gallego).

"La vida literaria. Aurelio Mitjans", Discusión (mar., 8).

"Picota literaria", Discusión (mar., 22). (Sobre Eugenio A. Flores, Francisco Gras, Francisco Salazar y Joaquín M. Bartrina).

"La vida errante" por Guy de Maupassant, Discusión (abr., 11), HE (abr., 13).

"Verdad y poesía", Discusión (abr., 26). (Sobre Zola).

"Libros nuevos: Pompeya por Aurelia Castillo de González", Discusión (jun., 6 y 7 ).

"Libros nuevos: Poesías de Francisco Sellén", Discusión (jul., 1). $10)$.

"José Ramón Betancourt", Discusión (jun., 25).

"Libros nuevos: Poesías de Francisco Sellén", Discusión (ju., 1).

"Apuntes biográficos de Juan Vilaró", Discusión (jul., 14). (Sobre un folleto de Antonio González Curquejo).

"Libros nuevos: Los Estados Unidos", por la marquesa de San Carlos de Pedroso, Discusión (jul., 21).

"En el cafetal", $H E$ (sept., 7). (Sobre novela de Domingo Malpica).

"Carta abierta a Carlos Noroña", $F$ (sept., 14). (Sobre Luis G. Urbina).

"José Fornaris. Recuerdos e impresiones", Pais (sept., 27).

"Crónica semanal", País (oct., 11). (Sobre Juan de D. Peza).

"Crónica semanal", País (nov., 22). (Sobre traducción de M. S. Pichardo).

"Crónica semanal", País (nov., 29). (Sobre folleto "Verdad y justicia").

\section{Cuentos y Poemas en Prosa}

"Cuentos amargos. Una madre", $H E$ (ene., 26).

"Ocios semanales. El mejor perfume, El velo de gasa", Discusión (mar., 12). (Son reproducciones, con algunas variantes).

"Ocios semanales. Dos encuentros", Discusión (mar., 21).

"Album de la ciudad. Retratos femeninos", Discusión (abr., 1).

"Para las mujeres. Introducción". I. "Japonería", A M. C., Discusión (abr., 2).

"Para las mujeres". II. "La estudiantina", A P. L. "En el tranvia", A J. J. L., Discusión (abr., 9). 
"Croquis femenino, fragmentos", Discusión (mayo, 12).

"Poema en prosa. Imitados de Baudelaire. Las quimeras, Cuál es la verdadera", Discusión (may., 31).

"Croquis femenino", Discusión (jun., 3).

"Croquis femenino, Derrochadora", Discusión (jun., 3).

"Caprichos y fantasías, La invitación al viaje". Imitación de Baudelaire, Discusión (jun., 11).

"La cámara doble". Imitación de Baudelaire, Discusión (jun., 6).

"Historias amargas. La viudez eterna", Discusión (jun., 20).

"Historias amargas. Una madre", Discusión (jun., 28).

"Historias amargas. El primer pesar", $H E$ (agos., 1).

"Historias amargas. La casa del poeta", HE (agos., 17).

"Historias amargas. La tristeza del alcohol", $H E$ (agos., 31). Sobre "El gato negro", de Poe. (Reproducida en "El Ateneo de El Salvador", v. III, sep. 1915, según cita de J. E. Englekirk).

\section{CRÍtica de ARte}

"Armando Menocal", Discusión (feb., 13).

"Exposición de retratos", Discusión (feb., 24).

"Armando Menocal. Nuevos retratos", Discusión (mar., 3).

"Conservatorio de música. Un coro de Wagner", Discusión (mar., 31).

"El Conservatorio de música. Un concierto", Discusión (may., 3).

"Siluetas de artistas. Guillermo Collazo", Discusión (mar., 21). (Este artículo pertenece a la serie "La sociedad de La Habana").

"El arte japonés", Discusión (jun., 17).

"Siluetas artísticas. Claudio Brindis de Salas", Discusión (jun., 24).

"Academia de pintura. Dos cuadros", Discusión (jul., 11).

"Crónica semanal. José Arburu", País (oct., 4).

"Crónica semanal. Espadero", País (oct., 11).

"Crónica semanal. Arburu", País (nov., 8).

"Conversaciones dominicales. El Fígaro ilustrado", País (dic., 27).

\section{CróNICAS}

"Año nuevo", Discusión (ene., 3).

"Fuera de la ciudad. Un jardín", Discusión (ene., 14).

"Noches morosas", Discusión (ene., 15).

"El Congreso médico", Discusión (ene., 16). 
"Fuera de la ciudad. Un hotel francés", Discusión (ene., 23).

"El Centro Gallego", Discusión (ene., 25).

"Al borde del abismo", Discusión (ene., 27).

"Bazar de los pobres", Discusión (ene., 29).

"El canal de Vento", Discusión (feb., 1).

"Fiestas literarias. Academia calasancia", Discusión (feb., 14).

"Salones habaneros. Gran baile de trajes", Discusión (feb. 15).

"El Conde de París en La Habana" Discusión (feb., 20).

"La agonía del carnaval", Discusión (feb., 22).

"El Conde de París", $H E$ (feb., 3).

"Reliquia histórica", Discusión (feb., 28).

"El Conde de París. Anécdota de ayer", Discusión (mar., 1).

"Album de la ciudad. I Frío. II En Tacón", Discusión (mar., 6).

"A bordo del Orizaba", Discusión (mar., 7).

"Album de la ciudad. El Fénix", Discusión (mar., 13).

"Album de la ciudad. Un sacerdote ruso", Discusión (mar., 14).

"Los libros útiles. Una aritmética", Discusión (mar., 28).

"Semana Santa. I Sensaciones personales. II Los oficios. III Las estaciones. IV La retreta", Discusión (abr., 5).

"La herodiada perruna", Discusión (abr., 17).

"Noches azules. Un gran matrimonio", Discusión (abr., 21).

"Todavía los perros", Discusión (abr., 22).

"Bocetos habaneros. I Un asilo. II Un baile", Discusión (may., 16).

"Bocetos habaneros. Entre los escombros", Discusión (may., 2).

"Através de la vida. Miguel Eyraud", Discusión (may., 28).

"Bajo la lluvia", Discusión (may., 30).

"Las últimas catástrofes", Discusión (jun., 2).

"A través de la ciudad. La paleta dorada", Discusión (jun., 4).

"Bocetos sangrientos. El matadero", Discusión (jun., 12).

"Un vapor. El Nantes", Discusión (jun., 13).

"Honores póstumos", Discusión (jun., 18).

"Album de la catástrofe. Reseña histórica", Discusión (jun., 19).

"Bocetos habaneros. Un café", Discusión (jul., 5).

"Salones habaneros. Una recepción", Discusión (jul., 7).

"Crónica semanal", País (oct., 18).

"Crónica semanal", País (oct., 24).

"Crónica semanal", País Anov., 1).

"Crónica semanal", País (nov., 15).

"Crónica semanal. Boda de Enrique Hernández Miyares", País (nov., 29). 
"Crónica semanal", País (dic., 6).

"Crónica semanal", País (dic., 13).

"Crónica semanal", País (dic., 20).

\section{Crónicas de Teatro}

Publicadas en el periódico La Dissusión, bajo el nombre genérico de "Veladas teatrales".

"Notas teatrales" (ene., 18).

"Teatro de variedad" (ene., 24).

"San Isidro" (ene., 28).

"Dos estrenos" (feb., 4).

"La nueva empresa" (feb., 12).

"Los payasos norteamericanos" (feb., 27).

"La señorita Ina Lasson y las hermanas Joran" (mar., 4).

"Nanón" (mar., 10).

"Veladas teatrales" (mar., 10).

"Rip-Rip" (mar., 15).

"Nuevo tenor" (mar., 18).

"Una tiple más" (mar., 20).

"E1 caballero Hermann" (mar., 24).

"Entre bastidores" (mar., 26).

"La cola del diablo". (mar., 27).

"En Irijoa" (mar., 29).

"Soledad Goizueta" (abr., 8).

"Amparo Cuevillas" (abr., 14).

"El hombre del cornetín" (abr., 15).

"El gran mogol" (abr., 18).

"Un cornetinista" (abr., 23).

"La Traviata" (abr., 24).

"Colegio de señoritas" (may., 1).

"El circo oriental" (may., 6).

"Un concierto" (may., 7).

"Un Ave Maria" (may., 10).

"Rigoleto" (may., 13).

"Las dos potencias" (may., 14).

"Burón y perecito" (may., 17).

"Círculo Habanero. Divorciimonos de V. Sardou" (may., 4).

"Militares y paisanos" (jun., 21).

"Tanhauser el estanquero" (jul., 4). 


\section{1}

POESIAS

"Madrigal. En el álbum de la Srita. Myrta Martínez Ibor", $F$ (ene., 11).

"Album femenino. A María Cay", F (mar., 8).

"Para el álbum de la Srita. Mercedes Marty y Carrillo", $H E$ (mar., 14). "Pastel japonés. A María Cay", HE (mar., 22). En Nieve con el título Kakemono").

"Sonrisas negras. A mi madre. Tras una enfermedad", HE (abr., 2).

"Nostalgias", $H E$ (abr., 12).

"Bajo-relieve", $H E$ (abr., 19).

"A la primavera", HE (may., 3).

"La reina de la sombra. A Rubén Darío, Guatemala", $H E$ (may., 10).

"Bocetos antiguos. La agonía de Petronio", HE (may., 17).

"Marfiles viejos. A mi padre", Pais (jun., 1).

"Paisaje de verano", País (jun., 23).

"Marfiles viejos. A la castidad. Revelación", $H E$ (jul., 19).

"Al carbón", $H E$ (jul., 26).

"Prometeo". (Cuadro de Gustavo Moreau), HE (agos., 16).

"Mi museo ideal. Cuadros de Gustavo Moreau", HE (agos., 30).

"Canas", La Habana Literaria (dic., 15).

"Canción. Para la niña Aurelia Aróstegui", $F$ (dic., 27).

"Sueño de gloria". Apoteosis de Gustavo Moreau, La Habana Literaria (dic., 30).

\section{CRóNICAS}

"Conversaciones dominicales. Días de campo", País (ene., 3).

"Albertini y Villate", País (ene., 9).

"Lohengrin", País (ene., 17).

"Esteban Borrero Echevarria", Pais (ene., 25).

"Teatro de Payret", Patis (ene., 31).

"Las memorias de Cora Pearl", País (feb., 7).

\section{Crítica LITERARIA}

"Libros nuevos. Artículos y discursos", por Enrique José Varona, $H E$ (abr., 26).

"Aurelia Castillo de González", HE (jul., 12).

"Rubén Darío: Azul y A. de Gilbert", La Habana Literaria (nov., 15). 


\section{CRÍtica de ARte}

"Pintores cubanos. José Arburu y Morell", La Habana Literaria (nov., 30).

1892

\section{PoEsías}

"Gustavo Moreau", F (ene., 15).

"Marfiles viejos. Inquietud y A un dictador", Habana Literaria (ene., 30).

"Album femenino. Srita. Hortensia del Monte", $F$ (ene., 31).

"Tipos españoles", A Enrique Hernández Miyares, I, "Una maja"; II, "Un torero"; III, "Un fraile", Habana Literaria (feb., 15).

"Alicia Sierra y Peñarredonda, Para su álbum", Habana Literaria. (feb., 29).

"En un hospital", Habana Literaria (mar., 3).

"Introducción" (De Nieve), El Hogar (abr., 8).

"A la belleza", Habana Literaria (abr., 15).

"Nihilismo", Habana Literaria (jun., 15).

"Galería infantil. Serafina Valdivia", $F$ (jun., 26).

"Marina, para Juana Borrero, pintora y poetisa", $F$ (jul., 10).

"Coqueteria", F (agos., 7).

"Sourimono, para un abanico de la señora De Valdivia", Habana Literaria (agos., 15).

"Obstinación", El Eco de las Damas (agos., 21).

"Galería infantil. Juana Borrero", El Hogar (agos., 28).

"Rondeles", Habana Literaria (agos., 30).

"Recuerdo de la infancia", F (sept., 4).

"Vieja historia", Habana Literaria (sept., 15).

"Poesías diversas, La sotana", etc. Habana Literaria (sept., 30).

"Album femenino, Corina Rowlan y del Monte", $F$ (oct., 2).

"Día de fiesta", País (oct., 14).

"Tres sonetos: ¡Oh altitudo!; A un héroe; Profanación", Habana Literaria (oct., 30 ).

"Las alamedas", Habana Literaria (nov., 15).

"Colón en la Rábida", 16 de noviembre de 1892. Belén (revista del Colegio de Belén), enero de 1932, año 7, núm. 3.

"Aegri somnia", Habana Literaria (nov., 30).

"Medioeval", Habana Literaria (dic., 15). 
Prosa

"Joris Karl Huysmans", Habana Literaria (mar., 15).

"Juana Borrero", Habana Literaria (jul., 15).

1893

PoEsías

"La cólera del infante", $H E$ (ene., 8).

"Bohemios", $H E$ (ene., 5).

"Páginas de vida", $H E$ (ene., 22).

"Neurosis", $H E$ (feb., 5).

"Dolorosa", $H E$ (feb., 19).

"Nocturno", HE (mar., 5). (En Bustos y Rimas como "Laus noctis").

"Vespertino", $H E$ (abr., 2). (En Bustos y Rimas como "Crepuscular").

"Esquivez", $H E$ (abr., 16).

"Voe soli. Preocupación", $H E$ (may., 7).

"A un poeta. Ruego", $H E$ (may., 14).

"Para una muerta", HE (may., 21).

"Oración. Las horas", $H E$ (agos., 13).

"Virgen triste", $H E$ (agos., 20).

"En el campo", HE (agos., 27).

"Sensaciones. Para el niño Gonzalo Aróstegui", País (agos., 23).

"Tardes de lluvia", $H E$ (sept., 3).

"Un santo. El hijo espurio", $H E$ (sept., 10).

"Enrique Gómez Carrillo,, HE oct., 1).

"Cuerpo y alma", HE (oct., 29).

"A Charito", El Hogar (nov., 19).

\section{CRÓNICAS}

"Rubén Darío. Dedicado a Enrique Gómez Carrillo, en París", $H E$ (e.e.e, 15).

"La última ilusión", $H E$ (ene., 29).

"Seres enigmáticos. El hombre de las muletas de níquel", $H E$ (feb., 12).

"El amante de las torturas", $H E$ (feb., 26).

"Esbozo de mujer", $H E$ (mar., 12).

"Aguafuerte. Medianoche", $H E$ (abr., 9).

"Bonifacio Byrne", $H E$ (abr., 30). 
"Bustos literarios. Dr. Francisco de Zayas. Mi libro de Cuba; Lola Ru. dríguez de Tió", $H E$ (oct., 22). (Sin firma. Según el testimonio cie Aniceto Valdivia en El Pais, octubre 1893).

"Pensamientos". Correspondencia inédita, $H E$ (oct., 29). (Repetidas ca Socictl, marzo 1923, por J. A. Fernández de Castro).

\section{EDICIONES}

"Hojas al Viento" (primeras poesías), Habana, Imprenta El Retiro, Amargura número 10, 1890.

"Nieve. (Bocetos antiguos. Mi Museo ideal. Cromos españoles. Marfiles viejos. La gruta del ensueño)", Habana, Imprenta La Moderna, Compostela 69, 1892.

"Nieve", editorial "El Intransigente", México, 1893.

"Bustos y rimas. (Ars religio nostra)", Habana, Biblioteca de "La Habana Elegante", Imprenia La Moderna, Compostela 69, 1893.

Estas ediciones fueron autorizadas por el poeta, aunque no se sabe a ciencia cierta cuál es el origen de la edición mexicana de Nieve, de la cual no había ejemplares accesibles en la ciudad de La Habana. La cronologia de otras ediciones y la bibliografía sobre Casal puede consultarse en el trabajo de Rita Geada de Prulletti, Revista Iberoamericana, número 63, enero-junio de 1967.

Esperanza Figueroa Amaral

Elmira College 
